\title{
Nickel-Copper Alloys Modified Electrodes: an Electrochemical Study on their Interfacial and Supercapacitive Properties
}

\author{
Franciele Wolfart, ${ }^{a}$ Bianca R. Brito, ${ }^{a}$ Luís F. Marchesi ${ }^{a, b}$ and Marcio Vidotti ${ }^{*, a}$ \\ ${ }^{a}$ Grupo de Pesquisa em Macromoléculas e Interfaces, Departamento de Química, \\ Universidade Federal do Paraná, CP 19032, 81531-980 Curitiba-PR, Brazil \\ ${ }^{b}$ Universidade Tecnológica Federal do Paraná, Av. Monteiro Lobato, s/n, km 04, \\ 84016-210 Ponta Grossa-PR, Brazil
}

\begin{abstract}
In this manuscript, we report the electrodeposition of nickel-copper alloys in a two steps methodology. Firstly, the copper electrode is oxidized to generate $\mathrm{Cu}^{2+}$ ions followed by the reduction of both $\mathrm{Ni}^{2+}$ and $\mathrm{Cu}^{2+}$. The electrodes were further cycled in $\mathrm{KOH}$ to convert the metallic alloy into the respective electroactive hydroxide. This methodology created an electrode with high roughness and distinct electrochemical behavior. The modified electrodes were also characterized by electrochemical impedance spectroscopy (EIS) and scanning electron microscopy (SEM). Finally, the modified electrodes were studied in their supercapacitive properties by galvanostatic charge and discharge curves; the electrodes showed a good specific capacitance of $58 \mathrm{mF} \mathrm{cm}^{-2}$. The results indicated a new strategy using a simple methodology to modified $\mathrm{Cu}$-electrodes to develop supercapacitors at low cost.
\end{abstract}

Keywords: nickel-copper hydroxides, supercapacitors, electrodeposition, interfacial properties

\section{Introduction}

Nowadays, the worldwide demand for energy impacts the research in new energy storage and conversion devices where it is intended an enhanced efficiency, low-cost and eco-friendly alternative.$^{1-3}$ Among them, supercapacitors (SCs) arise as a good alternative due to their ease-preparation, long cycle life and fast and reversible redox reactions. ${ }^{4-6}$ Supercapacitors, ultracapacitors or electrochemical capacitors are devices that combine the power delivery presented in the capacitors and the energy density presented by the batteries. ${ }^{7}$ Based on the charge storage mechanism, supercapacitors can be divided into two categories: electrochemical doublelayer capacitors (EDLCs), where the capacitance arises from the charge accumulated at the electrode/electrolyte interface. Carbonaceous materials such as graphene and carbon nanotubes are typical examples vastly employed in EDLCs. ${ }^{89}$ The second one are the pseudocapacitors, which the charge storage mechanism is based on both double layer capacitance and fast redox reactions at the electrode/electrolyte interface, increasing the overall density of current produced. Typical pseudocapacitors

*e-mail: mvidotti@ufpr.br materials are transition metals oxide/hydroxide $(\mathrm{TMOH})$ and conducting polymers. ${ }^{10-12}$

Amongst the different TMOH used as supercapacitors electrodes, $\mathrm{RuO}_{2}$ is by far one of the most investigated material due to its high theoretical specific capacitance, long cycle life and rate capability, electrochemical properties and conductivity. ${ }^{13}$ However, its high-cost and scarcity is the main drawback related to $\mathrm{RuO}_{2}$ based materials in commercial devices. In this way, in order to obtain more attractive materials, TMOH alloys based on low-cost metals have been extensively studied. ${ }^{14}$ Shinde et al. ${ }^{15}$ studied the incorporation of $\mathrm{Mn}$ in $\mathrm{CuO} / \mathrm{Cu}(\mathrm{OH})_{2}$ by successive ionic layer adsorption and reaction (SILAR) technique. The authors have found an improved specific capacitance of $600 \mathrm{~F} \mathrm{~g}^{-1}$ for the doped material that was ascribed to a change in the morphology occasioned by the Mn doping effect.

Another TMOH of interest is the versatile $\mathrm{Ni}(\mathrm{OH})_{2}$. This material presents many different applications, such as sensors, electrochromic electrodes, batteries, etc. ${ }^{16}$ and it is well reported in the supercapacitor technology. ${ }^{17}$ However, although $\mathrm{Ni}(\mathrm{OH})_{2}$ is a promising material to be employed as a pseudocapacitor material due to its high theoretical specific capacitance and low-cost, its poor 
cycle stability is the main drawback to be overcome. ${ }^{18}$ An alternative is to synthesize compounds based on mixed metals, adding a foreign atom in the nickel hydroxide structure. ${ }^{19,20}$ Zheng et al. ${ }^{21}$ studied a nickel-copper carbonate hydroxide hierarchical nanowire network electrode and found a specific capacitance of $971 \mathrm{~F} \mathrm{~g} \mathrm{~g}^{-1}$, an excellent long-life cycling stability and a retention capacity of $91.5 \%$ after 2000 cycles. Hierarchical $\mathrm{Co}_{3} \mathrm{O}_{4} @ \mathrm{Ni}-\mathrm{Co}-\mathrm{O}$ nanosheet-nanorod arrays was developed with high specific capacitance $25 \mathrm{~F} \mathrm{~cm}^{-2}$ retaining ca. $96 \%$ after 1000 cycles, indicating that the charge and discharge processes did not induce significant structural change in the electrode. ${ }^{19}$

It is well known that the electrode morphology plays an important role in the supercapacitor performance, to guarantee fast redox reactions at the electrode/electrolyte interface an intimate contact between them is desired. ${ }^{22,23}$ By this way, the electrode modification by the active material is a fundamental step to be analyzed. The simplest methodology can be described in terms of electrodeposition of electroactive materials. These methods are largely used to obtain different morphology and composites of transition metals. The facility on the fabrication, environmentally friendly and scalable at low cost advantages makes this technique very interesting in both academic and industry researches. ${ }^{24}$ Manganese oxide nanotubes are electrosynthesized by the cyclic voltammetric method. The easy and economical method of synthesis make this material useful for field-emission applications. ${ }^{25}$ Three-dimensional nanostructures of $\beta-\mathrm{Co}(\mathrm{OH})_{2}$ were synthesized by one-step electrodeposition process using a simple two-electrode system. ${ }^{26}$ By controlling the time of the voltage applied, the nanostructures were self-assembled from nanoplates to multilayered nanoplates building blocks showing higher specific capacitance values. ${ }^{26}$

Macroporous manganese oxide electrodes were prepared by template-assisted electrodeposition showing specific capacitance $60 \%$ higher than that obtained from flat surfaces, without loss of capacitance even after 1000 cycles. ${ }^{27}$ In addition, Tsai et al. ${ }^{28}$ reported the influence of the electrodeposition method on the morphology and capacitive properties of the electrodes. In this work, it was described the preparation of composites based on $\mathrm{MnO}_{2} / \mathrm{Ni}$ foams by three different methods: potentiodynamic (PD), potentiostatic (PS) and a combination of them (PS + PD). The $\mathrm{MnO}_{2} / \mathrm{Ni}$ electrodes obtained by (PS + PD) methodology showed higher specific area $\left(103 \mathrm{~m}^{2} \mathrm{~g}^{-1}\right)$ if compared with the electrodes prepared by PD $\left(21 \mathrm{~m}^{2} \mathrm{~g}^{-1}\right)$ and PS $\left(86 \mathrm{~m}^{2} \mathrm{~g}^{-1}\right)$ methods. The highly-porous structure of the (PS + PD) $\mathrm{MnO}_{2} / \mathrm{Ni}$ foams electrodes provides abundant space to the electrolyte transport into the electrode material resulting in excellent electrochemical performance. ${ }^{28}$
Also, Ni-Co double hydroxide nanocomposite were electrodeposited on porous $\mathrm{NiCo}_{2} \mathrm{O}_{4}$ nanowires previously grown on carbon fiber paper. The composites electrodes showed high specific capacitance $\left(1.64 \mathrm{~F} \mathrm{~cm}^{-2}\right)$ and long cycle life. ${ }^{29}$ In other contribution, the direct electrodeposition of nickel alloys was described and characterized in terms of their electrocatalytical properties..$^{30,31}$

As described above the advantages of the electrodeposition technique are very promising in the development of low cost materials in high scale and holds great potential for miniaturization of electrochemical devices. In this contribution, we describe a simple and direct electrodepositon of $\mathrm{Ni}-\mathrm{Cu}$ alloys directly onto low-cost copper electrodes. The modified electrodes were characterized by electrochemical techniques and by scanning electron microscopy (SEM). The electroactive interface obtained was deeply investigated in the construction of a high-performance electrode aiming the development of supercapacitors.

\section{Experimental}

$\mathrm{Ni}\left(\mathrm{SO}_{4}\right)_{2}, \mathrm{KOH}$ and $\mathrm{KCl}$ were obtained from Synth. The formation of $\mathrm{NiCu}$ metallic alloys onto copper electrodes followed the following steps: initially, in a $\mathrm{Ni}\left(\mathrm{SO}_{4}\right)_{2}$ solution $\left(10 \mathrm{mmol} \mathrm{L}^{-1}\right)$ it was applied an oxidative potential ( $E_{1}=0.7 \mathrm{~V}$ during 50 seconds) at the bare copper electrode $\left(\mathrm{A}=0.125 \mathrm{~cm}^{-2}\right)$ in order to remove $\mathrm{Cu}^{2+}$ ions from the electrode surface, then a reducing potential of $-1.1 \mathrm{~V}$ (during different times) was applied for the co-precipitation of metallic $\mathrm{NiCu}$ at the electrode surface. The conversion of metallic $\mathrm{NiCu}$ to the oxide/hydroxide form was done by cyclic voltammetry in $\mathrm{KOH} 1 \mathrm{~mol} \mathrm{~L}^{-1}$ at $20 \mathrm{mV} \mathrm{s}^{-1}$.

The electrochemical characterization was done in a IVIUM PGStat potentiostat. The cyclic voltammetry was studied between 0.1 and $0.65 \mathrm{~V}$ at different scan rates $\left(5,10,20,40,60,80\right.$ and $\left.100 \mathrm{mV} \mathrm{s}^{-1}\right)$ in $\mathrm{KOH} 1 \mathrm{~mol} \mathrm{~L}^{-1}$. The galvanostatic charge and discharge (GCD) tests were performed between 0.08 and $0.53 \mathrm{~V}$ at different current densities $\left(0.1,0.2,0.4,0.6,0.8\right.$ and $\left.1 \mathrm{~mA} \mathrm{~cm}^{-2}\right)$ in $\mathrm{KOH} 1 \mathrm{~mol} \mathrm{~L}^{-1}$. The electrochemical impedance spectroscopic data (EIS) were obtained at $0.1 \mathrm{~V}$ between $10 \mathrm{kHz}$ to $10 \mathrm{~Hz}$ and the ZView program was used to fit the experimental results. All electrochemical experiments were obtained in systems of the three-electrode cell using a large area platinum wire and $\mathrm{Ag} / \mathrm{AgCl} / \mathrm{Cl}^{-}{ }_{\text {sat }}$ as counter and reference electrodes, respectively. In addition, the electrodes were investigated by SEM with energy dispersive X-ray spectroscopy (EDS) in a FEI Quanta 450 FEG and EDS with $131 \mathrm{eV}$ resolution, Apollo detector X SDD. 


\section{Results and Discussion}

Initially, the copper electrode was submitted to different potential steps in $0.01 \mathrm{~mol} \mathrm{~L}^{-1} \mathrm{Ni}\left(\mathrm{SO}_{4}\right)_{2}$ electrolyte as described in the Experimental section. The first step occurs when applying a potential of $0.7 \mathrm{~V}\left(\mathrm{E}_{1}\right)$ for 50 seconds, to increase the electrode roughness and remove $\mathrm{Cu}^{2+}$ from the electrode surface. The second step is the co-precipitation of both $\mathrm{Cu}^{2+}$ and $\mathrm{Ni}^{2+}$ into the metallic alloy by applying $-1.1 \mathrm{~V}$. This potential is negative enough to perform the random co-deposition providing the morphological change at the electrode surface. The amperometric profile is shown in Figure 1, where it is possible to observe the intense anodic current indicating the continuous oxidation of the electrode to $\mathrm{Cu}^{2+}$ until the drastic change in the current direction in a diffusional like behavior, corroborating the reduction of ions from the bulk electrolyte. All depositions presented the same behavior regardless the time of deposition or electrolyte employed.

After the alloy formation, the next step is the conversion into the electroactive hydroxide. To do so, the modified electrodes were cycled in $\mathrm{KOH} 1.0 \mathrm{~mol} \mathrm{~L}^{-1}$. In Figure 2 are shown the cyclic voltammograms of the copper electrodes modified by the stripping time of 50 seconds and different reduction times $\left(E_{2}\right)$, in absence and presence of $10 \mathrm{mmol} \mathrm{L}^{-1}$ of $\mathrm{Ni}^{2+}$. It is important to mention that as reported elsewhere ${ }^{30}$ the first cycles of conversion have a different voltammetric shape reaching the stabilization after few cycles.

In the $\mathrm{NiCu}$ alloys, in all electrodes we can observe the presence of two oxidation process with a unique reduction wave, as longer the alloy formation (by applying different times of $E_{2}$ ) the higher the intensity of the first oxidation wave presents. Also, there is a clear shifting of the oxidation wave indicating that the $\mathrm{Cu} / \mathrm{NiCu}(\mathrm{OH})_{2}$ formed becomes more conductive material, as observed elsewhere when $\mathrm{Co}^{2+}$ is used as additive. ${ }^{23,31}$ The second oxidation process could be attributed to another crystallographic form of the alloy hydroxide, most similar to $\beta-\mathrm{Ni}(\mathrm{OH})_{2}$ probably with less amount of $\mathrm{Cu}^{2+}$ in the composite. Another experimental data that supports this point is the appearance of the intense oxidation process at higher applied potentials ascribed to the $\mathrm{O}_{2}$ reaction, typically catalyzed by the $\beta-\mathrm{Ni}(\mathrm{OH})_{2} \cdot{ }^{32}$ Also, at different scan rates the voltammetry cyclics (CVs) present a very discrete peak shifting towards more positive potentials, probably related to the internal resistance of the modified electrodes ${ }^{33}$ but the electrodes present an excellent reversibility, this fact can be attributed to the very rough surfaces, facilitating the ionic intercalation upon redox reactions. $^{34}$

In Figure 3 are shown the SEM images and the EDS spectra of the modified electrodes. Regardless the time of the alloy deposition, there is no apparent change in the size or form of the electrodeposited crystals, instead, a huge increase in the superficial roughness due to the increment of the crystals with the deposition time. It is not evident the precipitation of nanostructures of different morphologies, indicating the $\mathrm{Cu} / \mathrm{NiCu}(\mathrm{OH})_{2}$ composite formation. The SEM images by this way presented a highly electroactive surface, which is the main characteristic for any high performance electrochemical device.

The EDS analysis corroborated the presence of $\mathrm{Ni}$ in all modified $\mathrm{Cu}$-electrode (Figure 3e), confirming that the structures observed in the SEM are in fact composites and not $\mathrm{Cu}(\mathrm{OH})_{2}$ itself. At this point, it is important to mention that due to the low amount of electroactive material on the electrode surface, it was not possible to obtain accurately the real proportions of nickel and copper presented in the composite material, though all the experiments were very reproducible in the very same conditions tested. Although, the electrode modified with $5 \mathrm{~s}$ of $\mathrm{E}_{2}$ showed no peak of $\mathrm{Ni}$ in the EDS spectrum, the characteristic redox peak of $\mathrm{Ni}^{\mathrm{II}}(\mathrm{OH})_{2} / \mathrm{Ni}^{\mathrm{II}} \mathrm{OOH}$ is clearly present in the capacitance-voltage curves (Figure $2 b$ ) and in the SEM image (Figure 3a), confirming the presence of the $\mathrm{Ni}$ in the material. The absence of the Ni peak in the EDS spectrum can be attributed to the low time of $\mathrm{E}_{2}$, resulting in very
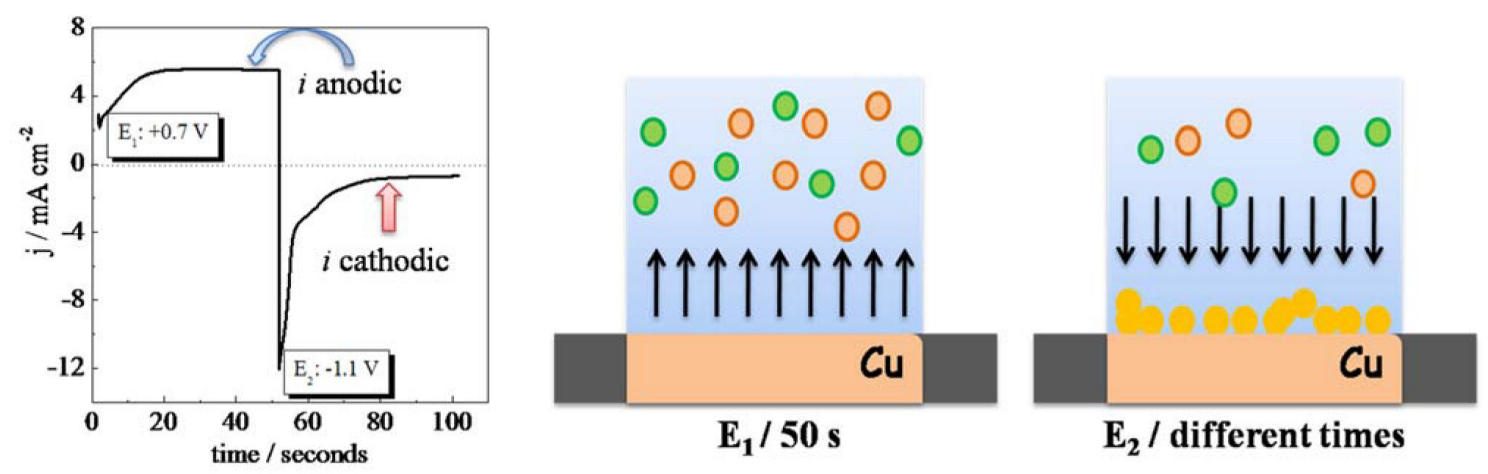

Figure 1. Amperometric profile of the electrode modification in $\mathrm{Ni}\left(\mathrm{SO}_{4}\right)_{2} 0.01 \mathrm{~mol} \mathrm{~L}^{-1}$ solution. Also, the scheme of the copper electrode modification is shown. The $\mathrm{E}_{2}$ was applied for different times to deposit different amounts of electroactive material. 

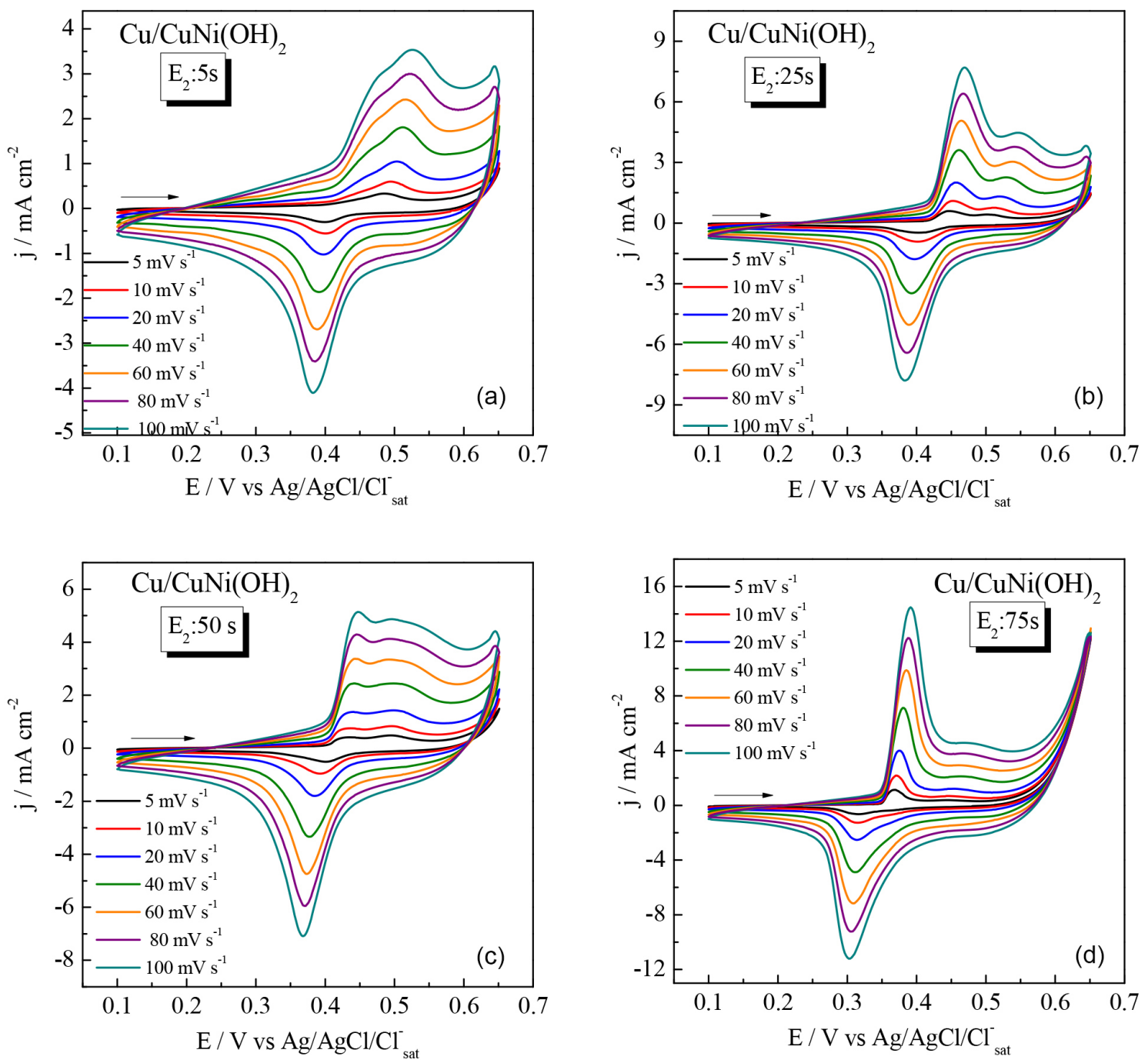

Figure 2. Cyclic voltammetry curves at various scan rate from $5-100 \mathrm{mV} \mathrm{s}^{-1}$ of $\mathrm{Cu} / \mathrm{NiCu}(\mathrm{OH})_{2}$ electrodes at different times of $\mathrm{E}_{2}$ : (a) $5 \mathrm{~s}$; (b) $25 \mathrm{~s}$; (c) $50 \mathrm{~s}$; (d) $75 \mathrm{~s}$. Electrolyte $\mathrm{KOH} 1 \mathrm{~mol} \mathrm{~L}^{-1}$.

small amount of $\mathrm{Ni}$ in the $\mathrm{Cu}$-electrode surface, in Figure 3a is possible to observe that the electrode is not completely covered with the composite nanostructure where large areas of unmodified copper are observed.

The SEM images and voltammetric results have shown modified electrodes with a large electroactive area and redox reversible behavior, resulting in charge accumulation characteristic of the pseudocapacitive materials. By this way, these modified electrodes can be effectively employed as active material in a supercapacitor device, where a fast and reversible intercalation process is very desirable. The pseudocapacitive experiments were performed in terms of the galvanostatic charge and discharge curves (GCDC) and the results are shown in Figure 4.

The GCDC measurements were performed to further evaluate the electrochemical performance of the electrodes regarding the supercapacitive properties (Figure 4). It is possible to observe an almost symmetrical non-linear
GCDC for all modified electrodes, indicating a good reversibility upon the redox process, as also depicted by the $\mathrm{CV}$ results, and the pseudocapacitance behavior. ${ }^{35} \mathrm{It}$ was also observed that an increase in the current density provokes a diminishment of the discharge time. In this way, the areal specific capacitance $\left(\mathrm{C}_{\mathrm{S}}\right)$ of the modified electrodes were calculated accordingly to equation 1 , as described elsewhere. ${ }^{36,37}$

$\mathrm{C}_{\mathrm{S}}=\frac{\mathrm{I} \times \mathrm{t}_{\mathrm{D}}}{\Delta \mathrm{V}}$

where $\mathrm{C}_{\mathrm{S}}$ is the areal specific capacitance $\left(\mathrm{mF} \mathrm{cm}^{-2}\right), \mathrm{I}$ is the applied current $\left(\mathrm{mA} \mathrm{cm}^{-2}\right), \mathrm{t}_{\mathrm{D}}$ is the discharge time (s), $\Delta \mathrm{V}$ is the potential range $(\mathrm{V})$. It is important to mention that there are many different methodologies to calculate $\mathrm{C}_{\mathrm{S}}$ found in literature, which might be difficult to compare the results. Nevertheless, our results can be readily 

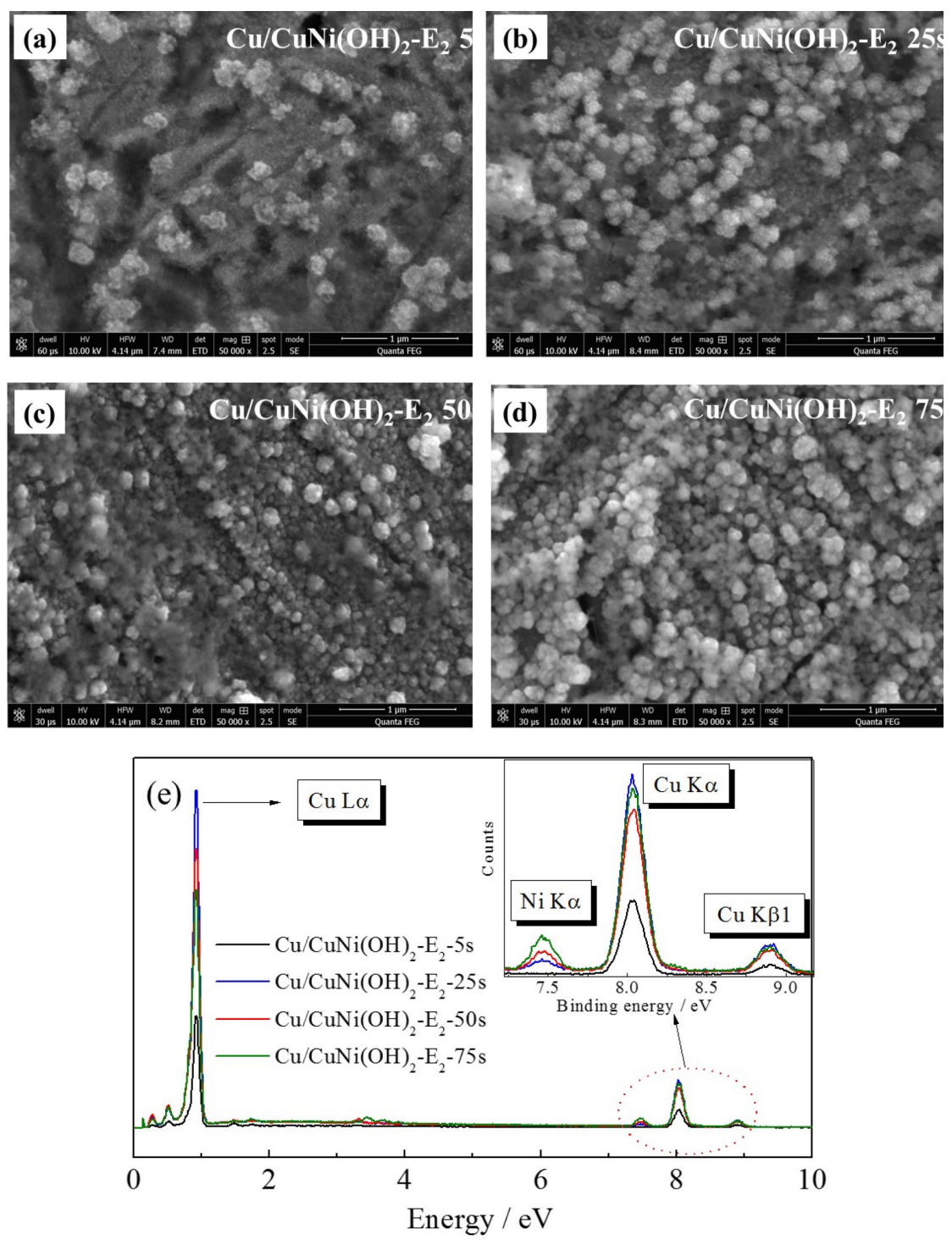

Figure 3. Representative SEM images obtained directly on the $\mathrm{Cu}$-electrode surface modified with $\mathrm{CuNi}(\mathrm{OH})_{2}$ at different time of $\mathrm{E}_{2}$ application (a) $5 \mathrm{~s}$; (b) $25 \mathrm{~s}$; (c) $50 \mathrm{~s}$; (d) $75 \mathrm{~s}$; (e) SEM-EDS obtained for all electrodes identified in the figure.

compared among them, pointing out the differences in the methodology of the electrode modification, which is the key factor of the present manuscript.

The $\mathrm{C}_{\mathrm{S}}$ calculated values for an applied current density of $0.1 \mathrm{~mA} \mathrm{~cm}^{-2}$ were $27,39,41$ and $58 \mathrm{mF} \mathrm{cm}^{-2}$ for the times of deposition of $5,25,50$ and $75 \mathrm{~s}$, respectively. The highest $\mathrm{C}_{\mathrm{S}}$ value presented by the $75 \mathrm{~s}$-modified electrode can be explained by the higher amount of the $\mathrm{Ni}$ deposited in this electrode increasing the number of intercalation sites. Although the values found to $\mathrm{C}_{\mathrm{S}}$ were not so high as others works concerning $\mathrm{Ni} / \mathrm{Cu}$ hydroxides, important features must be emphasized such as the simple and fast methodology and the low amount of electroactive material electrodeposited which guarantee the low cost for the electrode development using larger scales. Works published about $\mathrm{Ni} / \mathrm{Cu}$ electrodes can be cited, such as
$\mathrm{Ni}(\mathrm{OH})_{2}-\mathrm{Cu} /$ nickel foam electrodes presenting specific capacitance of $8.66 \mathrm{~F} \mathrm{~cm}^{-2}$ at $1 \mathrm{~mA} \mathrm{~cm}{ }^{-2}$ in $\mathrm{KOH} 2 \mathrm{~mol} \mathrm{~L}^{-1} \cdot{ }^{37}$ This higher value compared to ours can be attributed to the $\mathrm{Cu}$ network interwoven in the active material, providing a favorable electron-transport pathway and improve the conductivity of the electrode. ${ }^{37}$ However, the total time necessary to prepare the electrodes is around 17 hours with higher amount of material, while the electrodes presented herein can be build up in few minutes. Also, highly laborious multi-step copper modified electrodes such as $\mathrm{CuO} @$ layered double hydroxide core-shell nanoarrays presented higher values of $\mathrm{C}_{\mathrm{S}}$ of about 694,755 and $866 \mathrm{mF} \mathrm{cm}^{-2}$ for $\mathrm{CuO}, \mathrm{CoFe}-\mathrm{LDH}$ and $\mathrm{CuO} @ \mathrm{CoFe}-\mathrm{LDH}$, respectively. ${ }^{38}$ Furthermore, $\mathrm{Ni}-\mathrm{Cu}$ foams were electrodeposited onto stainless steel electrode by galvanostatic method. ${ }^{38}$ This technique is similar with our method in terms of both, fast 

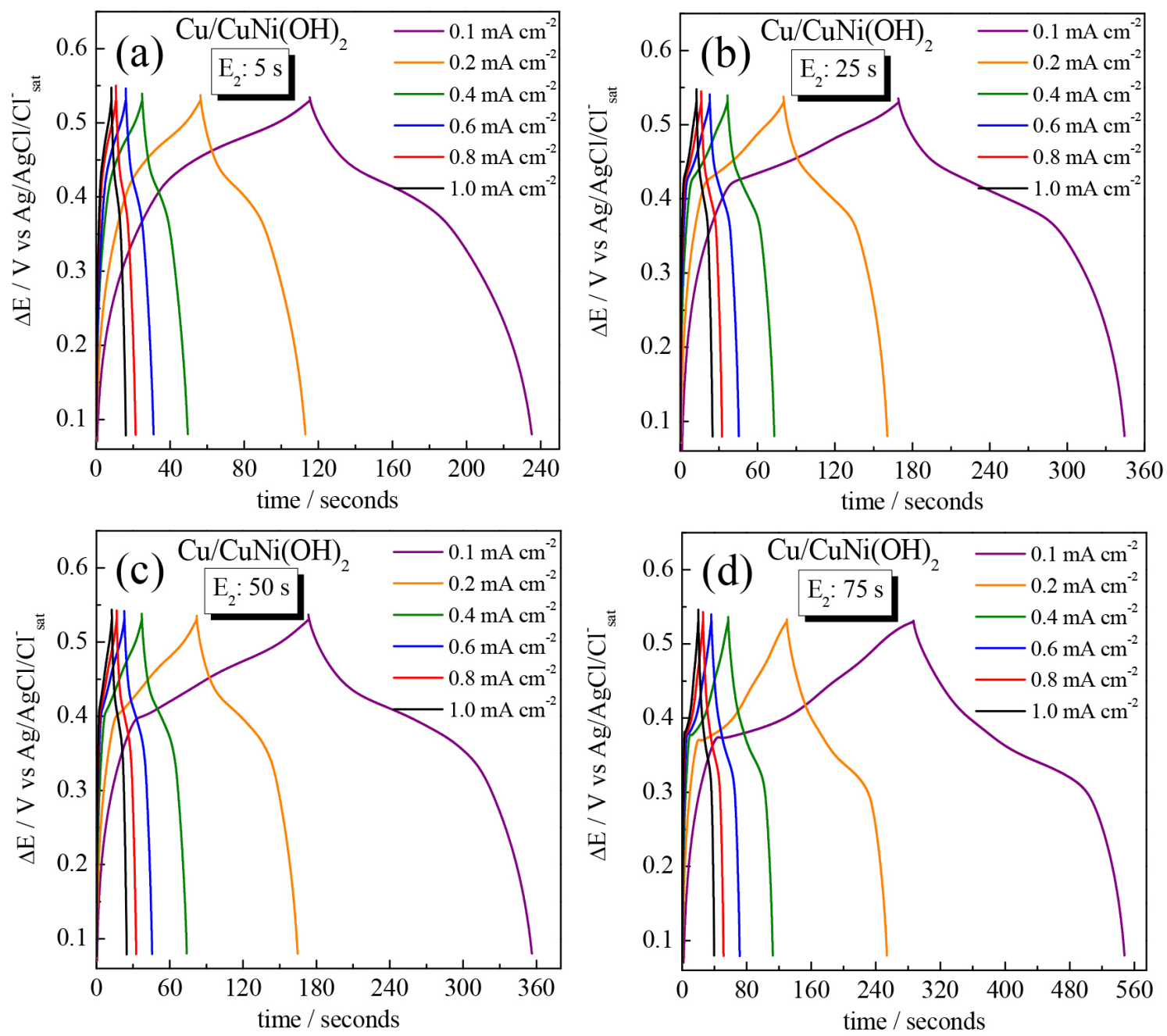

Figure 4. Galvanostatic charge and discharge curves at different current densities from 0.1 up to $1 \mathrm{~mA} \mathrm{~cm}{ }^{-2} \mathrm{of} \mathrm{Cu} / \mathrm{NiCu}(\mathrm{OH})_{2}$ electrodes. $\mathrm{Cu} / \mathrm{Ni}(\mathrm{OH})_{2}$ modified electrodes at different times of $\mathrm{E}_{2}$ : (a) $5 \mathrm{~s}$; (b) $25 \mathrm{~s}$; (c) $50 \mathrm{~s}$; (d) $75 \mathrm{~s}$. Electrolyte KOH $1 \mathrm{~mol} \mathrm{~L}^{-1}$.

and simple method to obtain of the electrodes, however, the specific capacitance was determined in terms of the mass of the electrode $\left(105 \mathrm{~F} \mathrm{~g}^{-1} \text { at } 1 \mathrm{~mA} \mathrm{~cm}^{-2}\right)^{38}$ making difficult the comparison of the values.

The Figure 5 shows the dependence of the $C_{S}$ on the applied current density for all modified electrodes. The increase of the current density provokes the diminishment of the $\mathrm{C}_{\mathrm{S}}$ values due to the diffusional process limitation where some electroactive sites are less available in faster charge intercalation. ${ }^{39}$ To verify the long-term stability, the capacity retention was measured as shown in Figure $5 \mathrm{~b}$ during 500 continuous cycling, applying $0.8 \mathrm{~mA} \mathrm{~cm}{ }^{-2}$, which is a higher current if compared with the best $\mathrm{C}_{\mathrm{S}}$ value found intending an accelerate durability test. For this experiment the electrode modified during $75 \mathrm{~s}$ of alloy deposition. It can be observed a decrease in the $\mathrm{C}_{\mathrm{S}}$ values with the number of cycles reaching $74 \%$ of the initial value after cycling, in agreement with similar works published elsewhere. ${ }^{15,40,41}$ Taking into account the higher current used for this experiment, the electrode presented a good durability. Many different aspects can be attributed to this behavior such as the loss of the material conductivity, the change in the morphology or the dissolution and detachment of the active material from the electrode surface. ${ }^{42-44}$

To better understand the interfacial properties of the $\mathrm{Cu} / \mathrm{NiCu}(\mathrm{OH})_{2}$ modified electrodes, electrochemical impedance spectroscopy (EIS) measurements were performed. The Nyquist plots are presented in Figure 6 where can be observed a typical EIS response concerning supercapacitors, ${ }^{45,46}$ i.e., a semicircle at the high-frequency region (inset), related to the Faradaic process, and a straight line at the low-frequency region, related to the load of intercalated charge within the film in order to maintain the charge neutrality upon oxidation process. ${ }^{47,48}$

The EIS responses were very similar, by this way, the equivalent circuit modeling was used in order to improve the discussion, as depicted in the Figure 6 and was also considered elsewhere in the interpretation of other modified 

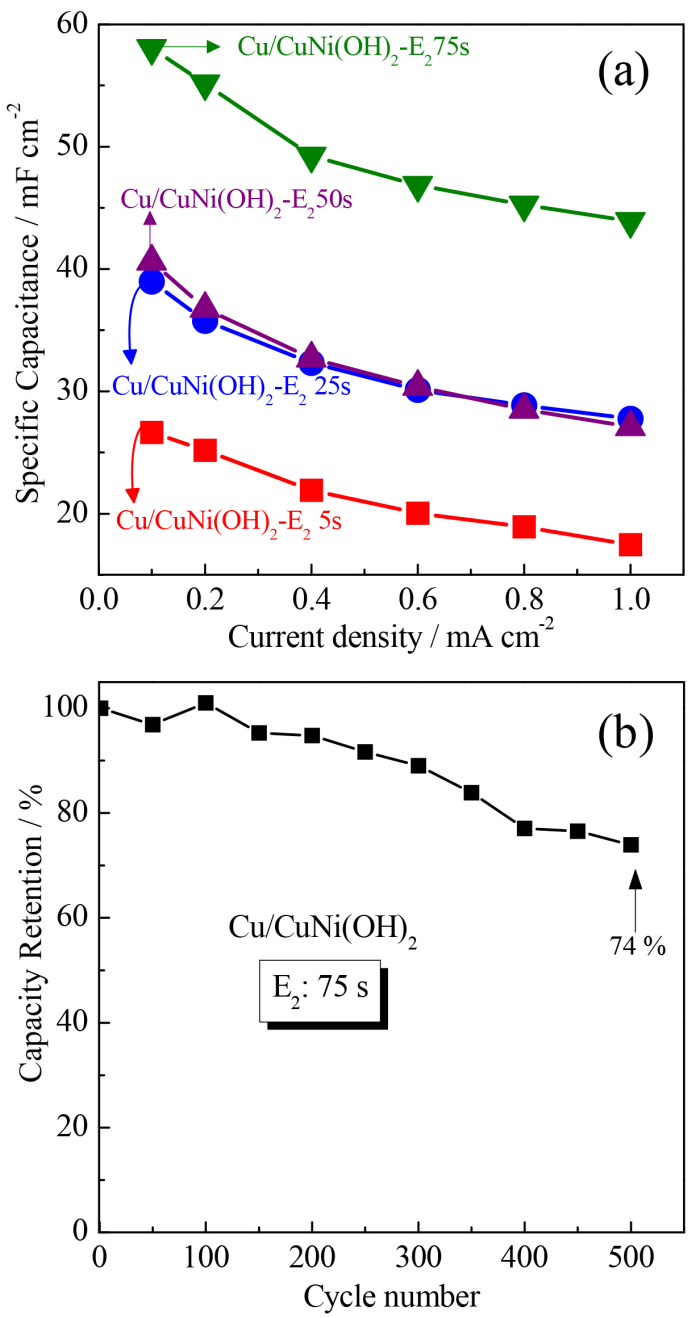

Figure 5. (a) Variation of specific capacitance with current density for all electrodes in $\mathrm{KOH} 1 \mathrm{~mol} \mathrm{~L}^{-1}$; (b) capacity retention of the $75 \mathrm{~s}$ modified electrode in an applied current density of $0.8 \mathrm{~mA} \mathrm{~cm}^{-2}$.

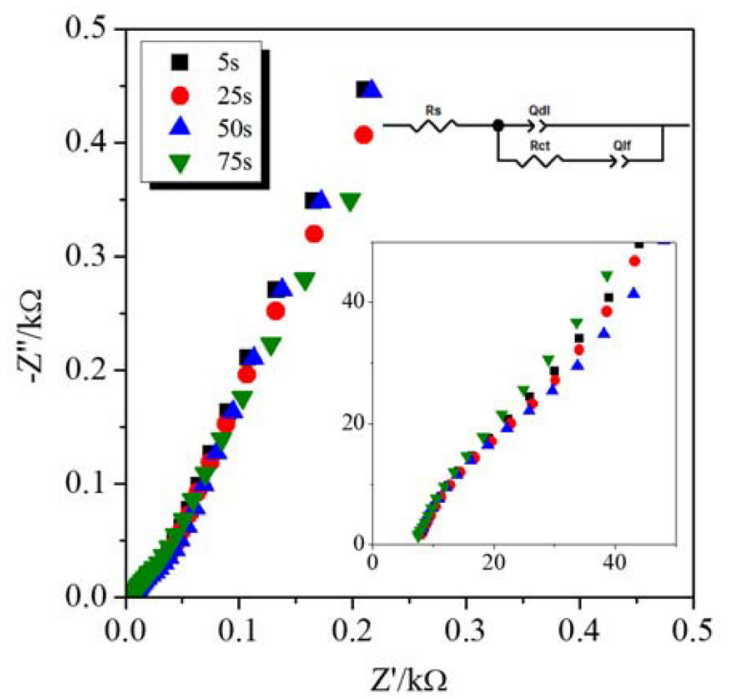

Figure 6. Nyquist plot at $0.1 \mathrm{~V}$ of the $\mathrm{Cu} / \mathrm{NiCu}(\mathrm{OH})_{2}$ modified electrodes obtained from different times of $\mathrm{E}_{2}$ alloy electrodeposition. Electrolyte $\mathrm{KOH} 1 \mathrm{~mol} \mathrm{~L}^{-1}$. electrodes ${ }^{49,50}$ where $R_{s}$ is the series resistance, accounting for the contacts and electrolyte resistances, $\mathrm{Q}_{\mathrm{dl}}$ is a constant phase element related to the double-layer capacitance, $\mathrm{R}_{\mathrm{ct}}$ is the charge-transfer resistance that accounts for the Faradaic process at the electrode/electrolyte interface, and the $\mathrm{Q}_{\mathrm{If}}$ element, which is another constant phase element, relating the low-frequency capacitance and so the quantity of intercalated charge within the film in order to maintain charge neutrality. The fitting results are summarized in Table 1.

Table 1. EIS related parameters calculated from the results presented in Figure 6 using the equivalent circuit model presented, $R>0.998, R_{S}$ : series resistance, $\mathrm{R}_{\mathrm{ct}}$ : charge-transfer resistance, $\mathrm{Q}_{\mathrm{dl}}$ : double-layer constant phase element and $\mathrm{Q}_{\mathrm{lf}}$ : low-frequency capacitance phase element

\begin{tabular}{lcccc}
\hline time $/ \mathrm{s}$ & $\mathrm{R}_{\mathrm{S}} / \Omega$ & $\mathrm{R}_{\mathrm{ct}} / \Omega$ & $\mathrm{Q}_{\mathrm{dl}} /\left(\mu \mathrm{F} \mathrm{s}^{\mathrm{n}-1}\right)$ & $\mathrm{Q}_{\mathrm{lf}} /\left(\mu \mathrm{F} \mathrm{s}^{\mathrm{n}-1}\right)$ \\
\hline 5 & 7.18 & 66.8 & 97.2 & 139.5 \\
25 & 7.50 & 45.7 & 60.2 & 210.2 \\
50 & 6.99 & 54.1 & 62.7 & 178.9 \\
75 & 7.03 & 58.1 & 106.3 & 226.5 \\
\hline
\end{tabular}

At this point, it is very important to mention that the $\mathrm{Q}_{\mathrm{dl}}$ values can be directly linked with the EDLC properties, as such parameters concern the electrode/electrolyte interface, on the other hand, the pseudocapacitive properties can be compared with the $\mathrm{Q}_{\mathrm{If}}$ values, as these parameters are related with the intercalated ions. In this way, the best supercapacitive properties accordingly to the EIS results is electrode modified by $75 \mathrm{~s}$ of alloy deposition (higher $\mathrm{Q}_{\mathrm{dl}}$ and $\mathrm{Q}_{\mathrm{If}}$ ), presenting the larger electrode/ electrolyte interface area and the higher number of intercalated ions, corroborating the GCDC results. Also it is important to mention that the $\mathrm{R}_{\mathrm{s}}$ and $\mathrm{R}_{\mathrm{ct}}$ values do not present considerable differences between the modified electrodes, supporting the discussion presented herein, by comparing the $\mathrm{C}_{\mathrm{S}}$ obtained from the GCDC curves and the EIS results. ${ }^{51,52}$

\section{Conclusions}

In summary, $\mathrm{Cu} / \mathrm{NiCu}(\mathrm{OH})_{2}$ modified electrodes were successfully prepared by a simple and straight forward methodology based on the oxidation of $\mathrm{Cu}^{2+}$ ions from the copper electrode followed by the coprecipitation of $\mathrm{NiCu}$ alloys by applying a reducing potential. Different times of deposition were tested creating different electroactive surfaces with increased roughness as observed by SEM and electrochemical experiments. The high electroactive area of the modified electrodes facilitates the ionic diffusion through the hydroxide matrix, improving the 
pseudocapacitive behavior. Specific capacitances of about $58 \mathrm{mF} \mathrm{cm}^{-2}$ were found; these values showed good agreement with the study of the EIS experiments in terms of both double layer capacitance and accumulated charges on the electroactive material. Finally, this work provides a good perspective to obtain energy storage devices employing low cost materials and simple methodologies.

\section{Acknowledgments}

The authors thank Brazilian agencies Fundação Araucária (308/2014) CAPES and CNPq (No. 473425/2014-0) for the financial support and Centro de Microscopia Eletrônica da UFPR (CME-UFPR) for the SEM and EDS facilities.

\section{References}

1. Jiang, L. L; Cong, S.; Lou, Y.-H.; Yi, Q.-H.; Zhu, J.-T.; Ma, H.; Zou, G.-F.; J. Mater. Chem. A 2016, 4, 217.

2. Li, S.; Zhang, H.; Zhao, W.; Ye, L.; Yao, H.; Yang, B.; Zhang, S.; Hou, J.; Adv. Energy Mater. 2015, 6, 1501991.

3. Dyatkin, B.; Presser, V.; Heon, M.; Lukatskaya, M. R.; Beidaghi, M.; Gogotsi, Y.; ChemSusChem 2013, 6, 2269.

4. Peng, Z.; Guo, Z.; Chu, W.; Wei, M.; RSC Adv. 2016, 6, 42019.

5. Zhao, K.; Liu, S.; Wu, Y.; Lv, K.; Yuan, H.; He, Z.; Electrochim. Acta 2015, 174, 1234.

6. Ferreira, C. S.; Passos, R. R.; Pocrifka, L. A.; J. Power Sources 2015, 271, 104.

7. Simon, P.; Gogotsi, Y.; Dunn, B.; Science 2014, 343, 1210.

8. Zhan, C.; Neal, J.; Wu, J.; Jiang, D. En.; J. Phys. Chem. C 2015, 119, 22297.

9. Rangom, Y.; Tang, X. S.; Nazar, L. F.; ACS Nano 2015, 9, 7248.

10. Long, X.; Wang, Z.; Xiao, S.; An, Y.; Yang, S.; Mater. Today 2016, 19, 213.

11. Huang, M.; Li, F.; Dong, F.; Zhang, Y. X.; Zhang, L. L.; J. Mater. Chem. A 2015, 3, 21380.

12. Feng, X.; Chan, N.; Zhou, J.; Li, Y.; Huang, Z.; Zhang, L.; Ma, Y.; Wang, L.; Yan, X.; New J. Chem. 2015, 39, 2261.

13. Shi, F.; Li, L.; Wang, X.; Gu, C.; Tu, J.; RSC Adv. 2014, 4, 41910.

14. Ozkale, B.; Mushtaq, F.; Fornell, J.; Chatzipirpiridis, G.; Martin, L. H. J.; Sort, J.; Mueller, C. M.; Pellicer, E.; Nelson, B. J.; Pane, S.; Electrochim. Acta 2016, 204, 199.

15. Shinde, S. K.; Dubal, D. P.; Ghodake, G. S.; Gomez-Romero, P.; Kim, S.; Fulari, V. J.; RSC Adv. 2015, 5, 30478.

16. Vidotti, M.; Torresi, R.; Torresi, S. I. C.; Quim. Nova 2010, 33, 2176.

17. Sk, M. M.; Yue, C. Y.; Ghosh, K.; Jena, R. K.; J. Power Sources 2016, 308, 121.

18. Dubal, D. P.; Gomez-Romero, P.; Sankapal, B. R.; Holze, H.; Nano Energy 2015, 11, 377.
19. Lu, Z.; Yang, Q.; Zhu, W.; Chang, Z.; Liu, J.; Sun, X.; Evans, D. G.; Duan, X.; Nano Res. 2012, 5, 369.

20. Ning, X.; Wang, X.; Yu, X.; Zhao, J.; Wang, M.; Li, H.; Yang, Y.; Sci. Rep. 2016, 6, 22634.

21. Zheng, X; Ye, Y.; Yang, Q.; Geng, B.; Zhang, X.; Chem. Eng. J. 2016, 290, 353.

22. Dubal, D. P.; Chodankar, N. R.; Gund, G. S.; Holze, R.; Lokhande, C. D.; Gomez-Romero, P.; Energy Technol. 2015, $3,168$.

23. Soares, A. L.; Marchesi, L. F.; Vidotti, M.; Electrochim. Acta 2016, 196, 670 .

24. Ribeaucourt, L.; Savidand, G.; Lincot, D.; Chassaing, E.; Electrochim. Acta 2011, 56, 6628.

25. Wu, M. S.; Lee, J. T.; Wang, Y. Y.; Wan, C. C.; J. Phys. Chem. B 2004, 108, 16331.

26. Nagaraju, G.; Ko, I. H.; Yu, J. S.; CrystEngComm. 2014, 16, 11027.

27. Benedetti, T. M.; Gonçales, V. R.; Petri, D. F. S.; Torresi, S. I. C.; Torresi, R. M.; J. Braz. Chem. Soc. 2010, 21, 1704.

28. Tsai, Y. C.; Yang, W. D.; Lee, K. C.; Hua, C. M.; Materials 2016, 9, 246.

29. Huang, L.; Chen, D.; Ding, Y.; Feng, S.; Wang, Z. L.; Liu, M.; Nano Lett. 2013, 13, 3135.

30. Wolfart, F.; Maciel, A.; Nagata, N.; Vidotti, M.; J. Solid State Electrochem. 2013, 17, 1333.

31. Wolfart, F.; Lorenzen, A. L.; Nagata, N.; Vidotti, M.; Sens. Actuators, B 2013, 186, 528.

32. Yeo, B., S.; Bell, A. T.; J. Phys. Chem. C 2012, 116, 8394.

33. Kuang, M.; Wen, Z. Q.; Guo, X. L.; Zhang, S. M.; Zhang, Y. X.; J. Power Sources 2014, 270, 426.

34. Deshmukh, P. R.; Bulakhe, R. N.; Pusawale, S. N.; Sartale, S. D.; Lokhande, C. D.; RSC Adv. 2015, 5, 28687.

35. Pedrós, J.; Boscá, A.; Martínez, J.; Ruiz-Gómez, S.; Pérez, L.; Barranco, V.; Calle, F.; J. Power Sources 2016, 317, 35.

36. Shi, D.; Zhang, L.; Yin, X.; Huang, T. J.; Gong, H.; J. Mater. Chem. A 2016, 4, 12144.

37. Eugénio, S.; Silva, T. M.; Carmezim, M. J.; Duarte, R. G.; Montemor, M. F.; J. Appl. Electrochem. 2014, 44, 455.

38. Li, Z.; Li, Z.; Shao, M.; Zhou, L.; Zhang, R.; Zhang, C.; Han, J.; Wei, M.; Evans, D. G.; Duan, X.; Nano Energy 2016, 20, 294.

39. Kim, B. K.; Sy, S.; Yu, A.; Zhang, J.; Handbook of Clean Energy Systems-Electrochemical Supercapacitors for Energy Storage and Conversion; John Wiley \& Sons, Ltd., 2015, DOI: 10.1002/9781118991978.hces112.

40. Lu, Z.; Chang, Z.; Liu, J.; Sun, X.; Nano Res. 2011, 4, 658.

41. Huang, L.; Chen, D.; Ding, Y.; Feng, S.; Wang, Z. L.; Liu, M.; Nano Lett. 2013, 13, 3135.

42. Sekar, P.; Anothumakkool, B.; Kurungot, S.; ACS Appl. Mater. Interfaces 2015, 7, 7661.

43. Pan, C.; Gu, H.; Dong, L.; J. Power Sources 2016, 303, 175. 
44. Xu, X.; Wang, Q.; Zhang, W.; Wang, Y.; Chen, W.; Electrochim. Acta 2016, 211, 1066.

45. Lin, H.; Huang, Q.; Wang, J.; Jiang, J.; Liu, F.; Chen, Y.; Wang, C.; Lu, D.; Han, S.; Electrochim. Acta 2016, 191, 444.

46. Wolfart, F.; Dubal, D. P.; Vidotti, M.; Gómez-Romero, P.; RSC Adv. 2016, 6, 15062.

47. Marchesi, L. F.; Jacumasso, S. C.; Quintanilha, R. C.; Winnischofer, H.; Vidotti, M.; Electrochim. Acta 2015, 174, 864.

48. Marchesi, L. F.; Pereira, E. C.; Synth. Met. 2014, 194, 82.
49. Hostert, L.; Alvarenga, G.; Vidotti, M.; Marchesi, L. F.; J. Electroanal. Chem. 2016, 774, 31.

50. Hostert, L.; Alvarenga, G.; Marchesi, L. F.; Soares, A. L.; Vidotti, M.; Electrochim. Acta 2016, 213, 822.

51. Xie, Y.; Xia, C.; Du, H.; Wang, W.; J. Power Sources 2015, 286, 561.

52. Tayel, M. B.; Soliman, M. M.; Ebrahim, S.; Harb, M. E.; Synth. Met. 2016, 217, 237.

Submitted: October 13, 2016

Published online: February 8, 2017 